\title{
Study on the Practice Course System of Business Administration
}

\author{
Jinying $\mathrm{Li}^{\mathrm{a},{ }^{*},}$ Tao $\mathrm{Pan}^{\mathrm{b}}$, Fan $\mathrm{Wu}^{\mathrm{c}}$
}

Department of Economic Management, North China Electric Power University, Baoding, China.

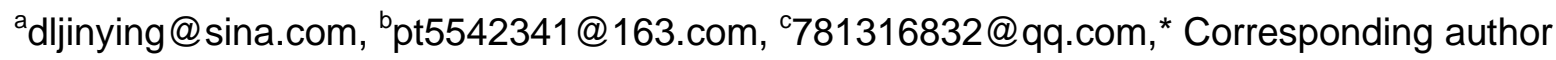

\author{
Keywords: Business Administration, Curriculum System, Practice Course
}

\begin{abstract}
Business Administration is the first level discipline of management category. Students who majored in Business Administration are required to master extensive theoretical knowledge of management and all kinds of professional skills. And the practice course takes up an important occupation in the teaching system which absolutely has an irreplaceable role. With the continuous development of social economy and the change of the demand for management talent, the traditional talent cultivation mode which always focuses on theoretical teaching but pays little attention to the practice training can no longer meet the demand of the employing unit for professional talents of Business Administration. Based on the facts above, this article, through contrasting different practice course systems of each university at home and abroad, mainly concentrates on analyzing the problems and weaknesses existing in these three aspects: the practice curriculum system, the implementation of process and the evaluation of the course. At the end of the paper, the author puts forward a series of suggestions and measures to improve the practice course system of Business Administration combined with the actual demand of the employing unit.
\end{abstract}

\section{Introduction}

As a comprehensive specialty, it requests students who majored in Business Administration to master extensive theoretical knowledge of management and all kinds of professional skills. But according to the feedback from employers, part of the enterprises hold the view that the undergraduate students of Business Administration are lack of the capability of practice and innovation which finally results in those students cannot maximize their advantages and characteristics. As an important part of the Business Administration's teaching system, the practice course plays an irreplaceable role in enhancing the overall quality of teaching and the students' practical ability. So it will be very necessary for universities to optimize the practice course of Business Administration and pay attention to the effect of the practice course, which finally helps the students develop the ability of practice and innovation. This paper takes Business Administration as the object of the study and through contrasting different practice course systems of each university at home and abroad, then it points out the problems and weaknesses existing in the practice training system of Business Administration. Combined with the actual demand of the employing unit for management talent and the characteristics of the university, this paper puts forward a series of suggestions and measures to improve the practice course system and helps to rethink the positioning of practice course of Business Administration, Furthermore, based on the characteristics of the school and talent training goal of the specialty, it also puts forward some advice about the development of the practice course system of Business Administration and the trend of the reform in college's practice education.

\section{The Comparison of the College's Practice Course Systems at Home and Abroad}

Analysis on the Practice Course of Business Administration in Domestic Colleges. We launched an investigation about the practice course system of Business Administration in six colleges, including North China Electric Power University, Central China Normal University, Shanghai Jiao Tong University, Tianjin University, Huazhong University of Science and Technology and Wuhan University. In terms of the number of the practice course, the proportion of the practice courses' credits reaches $23.3 \%$ in Tianjin University, which is the highest of the six universities studied. As 
to the course content, in addition to the graduation practice and the final thesis, the practice course of Business Administration in Central China Normal University, Shanghai Jiao Tong University, Huazhong University of Science and Technology and Wuhan University mainly involves metalworking, volunteer labor, social practice, productive labor and so on. And the practice course of Tianjin University contains just two modules: the curriculum design and the practice training. In the model of teaching, some colleges (such as Renmin University of China, Beijing Jiaotong University, etc.) have started to explore a full range and multi-level practice teaching model for students to carry out practical activities, including creativity experiment program, project survey, expert lectures and so on [1]. However, most domestic colleges still concentrate on traditional classroom teaching at present that students are lack of opportunities to join practice training totally on their own. Meanwhile, many new practical teaching modes are still at the exploratory stage which is quite hard to be promoted.

The Practice Teaching Modes of Business Administration in Foreign Colleges. Take the Harvard Business School for example, the practice course teaching of Business Administration in America usually pays more attention to case analyzing and practice teaching, which makes students adapt to the working environment after graduation in advance and improve their professional skills. Most American colleges require students majored in Business Administration to take part in social practice course ranging from 600 to 1300 hours. Meanwhile, their teaching mode is quite different from domestic colleges', which generally includes three aspects: classroom practice teaching, extracurricular practical training and practice course outside campus. In addition, many colleges choose to cooperate with enterprises to provide students the opportunity to participate in scientific research and improve their practical skills. By this way, enterprises can provide enough projects and funds for students and teachers to carry out the practice course effectively. In German, colleges adopts the "dual system" [2]to carry out practice teaching for management students. Through this model, it combines the theoretical knowledge education with practical skills teaching to realize the aim that university and enterprise co-cultivate talents. And the fund of practice teaching mainly comes from enterprises, which means enterprises dominate the whole process of practice teaching and the scientific research topics of practice teaching also originate from enterprise's demand. Most of the practice courses are evaluated by engineers from enterprises rather than teachers.

\section{The Demands of the Employing Units for Management Talents}

According the survey, we find that the ability and quality that management talents need to master mainly includes the following aspects:

The Ability of Innovation. China is in the transition periods of social development at present, and a series of policies bring great challenges for enterprises' development. Colleges should guide students to know more about the latest technology and mode of management to encourage students to take part in innovation activities actively, which is beneficial to build up the sense of innovation of students through learning advanced foreign management experience.

Communication and Cooperation. The definition of management refers to that the organization can make proper use of related resources by various functions, which aims to achieve the goal that cannot be achieved by individuals. The training target of Management talents is to make students have the ability to integrate individual and department of division into an efficient system. And they must have a certain expression of the ability to communicate to achieve the cooperation in different culture backgrounds.

Collecting Information and Processing Information. The marketing environment faced by enterprises is complicated and the efficiency of acquiring information and using information becomes a key factor to improve the core competitiveness of enterprises. Management talents are required to have the ability to collect information and process information by professional methods to gain high quality information timely.

Adapting to the Change. Management talents have to make accurate judgments and predictions based on all available information interior and exterior. And then, they must clear the key point of 
the enterprise's activities and make certain adjustments to adapt to the requirements of the enterprise's development. This process often involves three stages: thawing-change-freezing.

Professional Knowledge. As a successful management talent, student need to accumulate a large number of relevant professional knowledge which is necessary to the target position, including human resource management, marketing, project management and other basic knowledge of Business Administration.

\section{The Current Situation of the Practice Course of Business Administration}

Training Location Does not Meet the Needs of Enterprises. As the name suggests, the training objective is to realize the aim that equipping the students with skills which are necessary and then, we set the corresponding courses according to the training objectives [3]. Business Administration in our country is mostly established in 1980s. At present, different types of colleges and universities have set up different training objectives and mainly from the following: Training the people with management, economic, legal and business management knowledge and ability; Mastering the management theory and method and making the students have the ability of qualitative analysis and quantitative analysis; Having a background of certain natural science foundation and Engineering Science and technology. As listed above, the training target of business administration in our country trains the talented person who has some special skills, rather than the extensive knowledge and practical ability. The general talent can only meet the daily management of the enterprise business according to the current training target and the current educational pattern is unable to provide senior management personnel which can make major business decisions.

The Professional Teaching Materials Does not Meet the Requirements of the Times. Modern society is full of creativity and vitality and the rapid development of information technology have greatly changed people's thinking mode. So the teaching materials used in business administration education should keep pace with the times, and it should provide students with innovative thinking and broaden their horizons. But the textbook we used now is vacuous, inflexible and lack of innovation, which unable to attract the students' interest and stimulate creativity. The textbooks usually pay emphasis on theoretical knowledge but ignore the cultivation of practical knowledge, and the examples in the book did not match the real society. Such teaching materials are not worth promoting in business administration education.

The Teaching Methods Are out of Line With the Training Objectives. Similar to the teaching material of business administration, the teaching method is too old and rigid. [4,5] "Spoon feeding" teaching is the mainstream way of the teaching method nowadays. It is not suitable for Business Administration which requires a strong practical experience. There is not much communication between teachers and students, teachers and students cannot get effective communication between the ideas of curriculum. The "guide" and "heuristic" teaching method is not fully implemented. The teaching model focuses on the theory of instillation, but ignores the ability of finding problems. The most important is that teaching model can't culture the practical ability; business management is professions that focus on practical ability, that's to say we should train students to use professional knowledge to solve practical problems.

Teachers' Scientific Research Activities Does not Match Teaching Activities. At present, the objective of the teachers' scientific research activities in our country is to publish papers, professional title evaluation and calculation workload. It is out of line with the teacher's teaching activities. It seems that the teacher's main work is to publish papers and research topics, and the teaching activities have become a secondary side. As we all know, teaching is the most important work of teachers.

\section{Suggestions for the Improvement of Business Administration's Practice Course}

Constructing an Independent Practice Course System. As an important part of the talent developing system of Business Administration, colleges need to form a mutually connected and independent practice course system which is distinct from the theoretical knowledge teaching in 
order to realizing the goal that practice course training and theoretical knowledge teaching complement each other. All of the practice courses need the guidance of the theoretical knowledge and each practice course is interrelated, which forms a scientific and mutually connected practice course system through the optimization and integration of the practice courses.

Highlighting the Characteristics of Practical Course. Colleges should know about the demand of the employing unit for professional talents of Business Administration and the tendency of regional development timely. And then, based on the facts above, colleges are required to establish its own practice course system according to the characteristics of the college and the demand of the specialty, including the following three aspects: first, colleges should understand the requirement of employing unit for management talents by taking the mode of "school + enterprise" in its practice course teaching; second, colleges can highlight specific practical courses and construct its own practice course system; third, colleges should make adjustments to the course and update the practice course system according to the development of the society.

Making full Use of Practice Link and Innovating the Practice Teaching Mode. On the basis of using traditional practice teaching mode, such as board simulation, computer software and so on, colleges and teachers can try to explore a new mode of practice teaching. For example, colleges can cooperate with enterprises to establish a practice training base out of campus according to the specialty training scheme of Business Administration. And we can also encourage students to participate in some practice projects to carry out the practice course, such as the student's Platform for Innovation and Entrepreneurship Training Program, The Challenge Cup, etc.

Cooperation with Enterprises to Set up Simulation Program. The final service object of students majored in Business Administration is the major small and medium-sized enterprises. So the school should cooperate with the enterprise in the training process, and establish a stable cooperative relationship with enterprise. Schools set up simulation program cooperation with enterprises, students can simulate the business process. Enterprises provide the staff with rich experience to answer the questions in the simulation process ,as a result, the comprehensive ability of the students can be cultivate by the combination of the teacher's solid theoretical foundation and the enterprise staff's rich work experience. And our teachers can also integrate practice content into the classroom teaching to improve the quality of teaching.

\section{Conclusion}

Business Administration has a strong practical and application, and thus it is welcomed by the large and medium sized enterprises. However, the business management professional should advance with the times, in order to meet the needs of enterprises business administration needs to carry out continuous reform. Thus it can better service enterprises, service society, promote economic development, social development, and provide a solid backing for the rise of China's industry and commerce.

\section{Acknowledgments}

This work has been supported by "Professional comprehensive reform pilot project of Colleges and Universities”

\section{References}

[1] Zhu Bo qing, "Construction of practical teaching system of Business Administration,” J. The research of higher education in Heilongjiang. 2009. doi:10.3969/j.issn.1003-2614.2009.01.053

[2] Deng Li, "A comparative study on the talent training mode of Business Administration at home and abroad,”J. WORLD OF ENTREPRENEURS.2011,(4)

[3] Xu Dong and Xu Xu kan, "Constructing a new model of business administration professional training mode by ERP simulation laboratory platform,”J. Experimental technology and management. 
2003.doi:10.3969/j.issn.1002-4956.2003.06.034

[4] Zhang Wei, "Rearch on Comprehensive Practice Teaching Reform of Business Administration Major in Open Education,” J. Journal of Henan Radio \& TV University.2015,28(2)

[5] Wang Xingke, Nie Yuanyuan. New research on the teaching reform of Business Administration Major in Higher Vocational Education [J]. science and technology information, 2013, (4) 